BANCA D'ITALIA

E U R O S I S T E M A

Questioni di Economia e Finanza

(Occasional Papers)

The evolution of bad debt in Italy during the global financial crisis and the sovereign debt crisis: a counterfactual analysis

by Alessandro Notarpietro and Lisa Rodano

$$
350
$$





\section{Questioni di Economia e Finanza}

(Occasional papers)

The evolution of bad debt in Italy during the global financial crisis and the sovereign debt crisis: a counterfactual analysis

by Alessandro Notarpietro and Lisa Rodano

Number 350 - September 2016 
The series Occasional Papers presents studies and documents on issues pertaining to the institutional tasks of the Bank of Italy and the Eurosystem. The Occasional Papers appear alongside the Working Papers series which are specifically aimed at providing original contributions to economic research.

The Occasional Papers include studies conducted within the Bank of Italy, sometimes in cooperation with the Eurosystem or other institutions. The views expressed in the studies are those of the authors and do not involve the responsibility of the institutions to which they belong.

The series is available online at www.bancaditalia.it.

ISSN $1972-6627$ (print)

ISSN 1972-6643 (online)

Printed by the Printing and Publishing Division of the Bank of Italy 


\title{
THE EVOLUTION OF BAD DEBTS IN ITALY DURING THE GLOBAL FINANCIAL CRISIS AND THE SOVEREIGN DEBT CRISIS: A COUNTERFACTUAL ANALYSIS
}

\author{
by Alessandro Notarpietro* and Lisa Rodano*
}

\begin{abstract}
This paper presents the results of a counterfactual exercise that aims at quantifying the contribution to the evolution of bad debts made by the two recessions that have hit the Italian economy since 2008. The counterfactual simulations are performed using the Bank of Italy's Quarterly Model (BIQM). A 'no-crises scenario' is built for the period 2008-2015. The counterfactual dynamics of the main macroeconomic and financial variables are used to feed a simple model, in which the new bad debt rate depends on macroeconomic conditions and borrowing costs. The analysis suggests that, in the absence of the two recessions - and of the economic policy decisions that were taken to combat their effects - non-financial corporations' bad debts at the end of 2015 would have reached $€ 52$ billion, instead of $€ 143$ billion. The ratio of bad debts to the total amount of loans to non-financial corporations would have reached 5\%, a value in line with the pre-crisis period.
\end{abstract}

JEL Classification: E27, E37, E65, G21.

Keywords: business cycle, global financial crisis, sovereign debt crisis, banking, Italian economy.

\section{Contents}

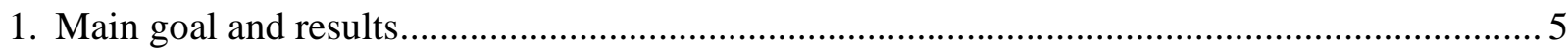

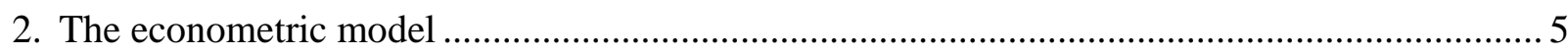

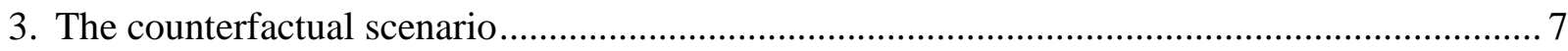

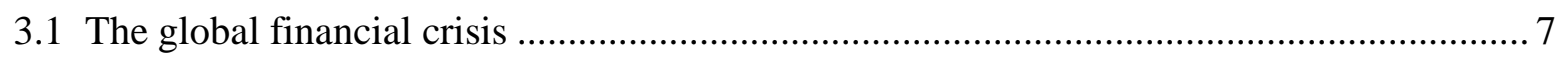

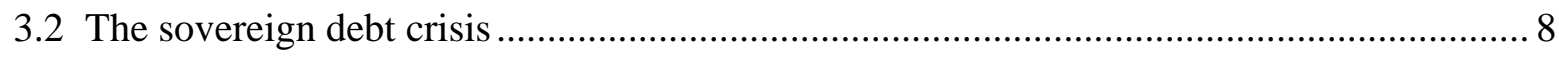

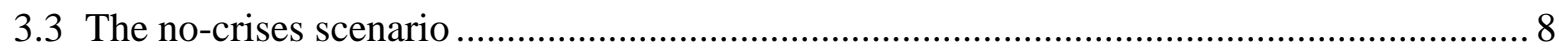

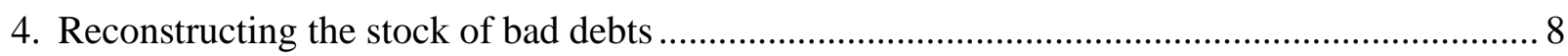

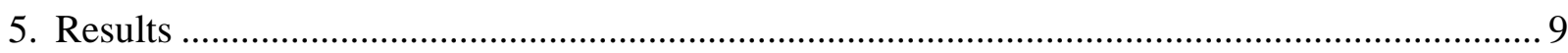

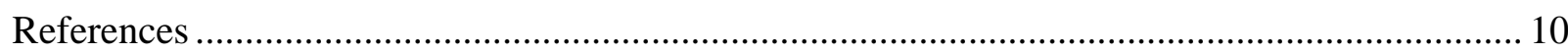

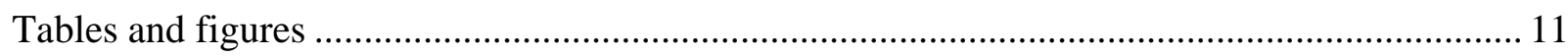

* Bank of Italy, Economic Outlook and Monetary Policy Directorate. 



\section{Main goal and results}

Bad debts as a share of total outstanding loans to non-financial corporations peaked to 17.9 per cent in December 2015. ${ }^{1}$ Their rapid growth in the last few years has reflected the large increase in the new bad debt rate, defined as the ratio between the flow of new bad debt and the total outstanding amount of loans net of bad debts. That rate began to increase in the wake of the global financial crisis and rose sharply during the sovereign debt crisis (Fig. 1).

This work illustrates the results of a counterfactual exercise that aims at quantifying the contribution to the evolution of bad debts of the two profound recessions that have hit the Italian economy since 2008. The counterfactual simulations, performed with the Bank of Italy Quarterly Model (BIQM), suggest that, in the absence of the two recessions - and of the economic policy decisions that were taken to combat their effects - non-financial corporations' bad debts at the end of 2015 would have reached $€ 52$ billion, instead of $€ 143$ billion (-63 per cent).

This analysis is based on two previous exercises, reported in Caivano, Rodano and Siviero (2010) and Busetti and Cova (2013). The former paper provides a quantification of the contribution of the global financial crisis to Italian GDP dynamics. The latter paper estimates the macroeconomic effects of the sovereign debt crisis. The exercise illustrated in this work makes use of both contributions to construct a "no-crises scenario" encompassing the whole period from 2008 to 2015. The counterfactual dynamics of the main macroeconomic and financial variables is used to feed a simple model, in which the new bad debt rate depends on macroeconomic conditions and borrowing costs. By cumulating the counterfactual flows of new bad debt, it is thus possible to build the counterfactual evolution of bad debts in Italy in the absence of the two crises. A similar analysis is conducted in Albertazzi, Notarpietro and Siviero (2016), where the dismal growth performance of the Italian economy is also found to be one of the main drivers of the observed increase in bad debt.

\section{The econometric model}

The historical evolution of bad debts is described by a block of equations of the BIQM, linking the new bad debt rate to macroeconomic and financial conditions.

In the following, the main properties of the equation for the non-financial corporations' new bad debt rate are described. Contrary to that of non-financial corporations, households' new bad debt rate grew moderately during the crises (Fig.1). In light of this, it is not considered in the counterfactual analysis below.

The equation included in the model used for this paper links non-financial corporations' new bad debt rate (BDIMP in the model) to: (i) the short-term real interest rate, (ii) firms' borrowing costs and (iii) deviations of output from its long-run level. As mentioned above, BDIMP is defined as follows:

\footnotetext{
* Banca d’Italia. E-mail: alessandro.notarpietro@bancaditalia.it; marialisa.rodano@bancaditalia.it.

${ }^{1}$ This work focuses on bad debts of non-financial corporations solely. A similar - though not strictly comparable figure for firms (including producer households) is usually reported in the Financial stability report of the Bank of Italy: in December 2015, bad debts of firms as a share of their total loans amounted to 17.7 per cent (see Banca d'Italia, 2016).
} 


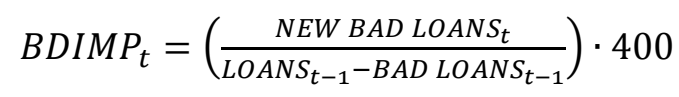

where $N E W B A D L O A N S_{t}$ denotes the flow of new bad debt, $L O A N S_{t-1}$ is the total outstanding amount of loans to non-financial corporations and $B A D L O A N S_{t-1}$ is the stock of bad debts. ${ }^{2}$

The model includes as a dependent variable a transformation (TBDIMP) that ensures non-negative values of the variable of interest and allows to capture possible non-linear effects related to the crisis periods:

$$
\operatorname{TBDIMP}_{t}=\log \left(\frac{\frac{B D I M P_{t}}{100}}{1-\frac{B D I M P_{t}}{100}}\right)
$$

The following specification is estimated on the 1991:4 - 2014:4 sample:

$$
\begin{array}{rlcc}
T B D I M P_{t}=-1.5175+ & 0.67173 * T_{B D I M P} \\
(-5.123) & (9.8265) & 0.0137 * T R_{t}-0.06734 * G A P_{t-1}+0.0026 * \text { ONFIN }_{t}
\end{array}
$$

T-statistics of the coefficients are in brackets. The $\mathrm{R}^{2}$ is 0.95 and the model passes the usual standard diagnostics. Table 1 reports the corresponding descriptive statistics. The term $T R_{t}$ is the real interest rate, here defined as the difference between the interest rate on loans to non-financial corporations and year-onyear, beginning-of-quarter consumer price inflation expectations. The term $G A P_{t}$ is a measure of the output gap, given by the percentage deviation of real GDP $\left(P I L R D_{t}\right)$ from its long-run level ${ }^{3}$ :

$$
G A P_{t}=100 *\left(\frac{\text { PILRD }_{t}}{\text { POTENTIAL OUTPUT }}-1\right)
$$

The term $O N F I N_{t}$ defines non-financial corporations' borrowing costs. The latter are computed as the ratio of total interest rate expenditures (interest rate on loans, $T I M P T_{t}$, multiplied by the total outstanding amount of loans, $\left.C R I M P C_{t}\right)$ and value added $\left(V A C I M P_{t}\right)$ :

$$
\operatorname{ONFIN}_{t}=\frac{\operatorname{TIMPT}_{t} * \operatorname{CRIMPC} C_{t}}{\operatorname{VACIMP}_{t}}
$$

The new bad debt rate increases when the real interest rate rises and, more generally, when firms' borrowing costs increase. By contrast, if GDP rises above its long-run trend, the rate of new bad debt declines: better macroeconomic conditions favor firms' profitability and therefore contribute to reducing the probability that loans will not be repaid.

\footnotetext{
${ }^{2}$ The expression on the right-hand side is multiplied by 400: (i) since the numerator and the denominator are both quarterly data, but the former is a flow and the latter is a stock, the numerator is multiplied by 4 in order to express everything in annual terms; (ii) the whole ratio is multiplied by 100 in order to express it in percentage points.

${ }^{3}$ GDP in the long run evolves in line with potential output as defined in the BIQM (see Parigi and Siviero, 2000).
} 
Figure 2 reports the response of $B D I M P_{t}$ to an increase of the output gap by 1 percentage point over a three year period. The fall in the new bad debt rate is gradual, reflecting the inertial component. Equation (3) captures possible non-linearities, which may have played a role in the course of the recent crises, given the large swings in $B D I M P_{t}$ in the course of them. Indeed, relevant nonlinear effects are manifest. With the output gap shock occurring in 2000, a peak (negative) response of about 0.25 percentage points (pp) is observed after 3 years. If the same shock hits the economy in 2007, the maximum effect reached after 3 years is roughly twice as large (-0.4 pp). Finally, if the shock is assumed to occur in 2010, the response of the new bad debt rate is even more rapid and larger, in absolute value.

\section{The counterfactual scenario}

A quantitative assessment of the impact of the two crises on the new bad debt rate and, as a result, on the total outstanding amount of non-financial corporations' bad debts in the Italian banking system is obtained by means of a counterfactual simulation. Using the BIQM, a "counter-history" was constructed, which simulates the evolution of the main Italian macroeconomic and financial variables that would have been observed under the assumption that some factors - identified as particularly relevant for the Italian economy - had followed a different path than the one actually observed since the summer of 2007. More specifically, the "counter-history" aims at reproducing, for each factor or set of factors, dynamics consistent with a "nocrises" scenario. The difference between such scenario and the observed historical data provides a measure of the role of the different channels in the transmission of the two crises to the Italian economy.

The construction of the "no-crises" scenario makes use of two previous exercises, reported in Caivano, Rodano and Siviero (2010) and Busetti and Cova (2013). The former paper provides a quantification of the contribution of the global financial crisis to Italian GDP dynamics. The latter paper estimates the macroeconomic effects of the sovereign debt crisis.

Based on the results of these two studies - and treating the global financial crisis and the sovereign debt crisis as a unique crisis episode, which occurred over a 6-year horizon (2008-2013) - the counterfactual analysis carried out in this exercise estimates an overall GDP loss due to the two crises of about 13 pp; this implies that, absent those crises, Italian GDP would have grown between 0.5 and 1 per cent per year between 2008 and 2013, somewhat below the average annual increase in the six years that preceded the global financial crisis.

In the following, more details are provided about the construction of the "no-crises" scenario.

\subsection{The global financial crisis}

In order to replicate the evolution of the Italian economy "as if" the events related to the global financial crisis had never materialized, in line with Caivano, Rodano and Siviero (2010) counterfactual assumptions were formulated for the following factors, which were directly affected by the crisis: (i) fall in world GDP and trade and repercussions on international prices and exchange rates ("imported crisis"); (ii) worsening of financing conditions for households and firms ("domestic financial factors"); (iii) impact on consumption of the fall in the price of assets held by Italian households ("wealth effects"); (iv) contraction in the domestic

components of aggregate demand not related to fundamental dynamics ("confidence crisis"). Among the indirect effects of the crisis one should also include the countermeasures undertaken by monetary and fiscal 
authorities. This was taken into account in the design of the counterfactual scenario, which therefore does not include the reaction of monetary and fiscal variables to the effects of the crisis.

\subsection{The sovereign debt crisis}

Concerning the sovereign debt crisis, in line with Busetti and Cova (2013), the following assumptions were made: (i) foreign demand, weighted for exports destination markets, expands in 2012-2013 at a growth rate similar to that observed in the decade before the global financial crisis; (ii) the exchange rate is kept fixed at the average level observed between end-June and the beginning of July 2011; (iii) oil prices are obtained from future contracts in the same period; (iv) the evolution of interest rates on Italian sovereign bonds reflects market expectations in the same period, which are consistent with a gradual increase in yields over the forecast horizon and an approximately constant 10-year BTP-Bund spread. As in the case of the global financial crisis, the reaction of monetary and fiscal policy to the effects of the crisis is removed from the counterfactual scenario.

\subsection{The "no-crises" scenario}

The above-mentioned assumptions are combined in order to create a "counter-history" consistent with a "no-crises" scenario. According to the estimates reported in Caivano, Rodano and Siviero (2010) the overall GDP loss attributed to the global financial crisis is about $6.5 \mathrm{pp}$ in the 2008-2010 period. The resulting GDP level at the end of 2010 in the counterfactual scenario is therefore about 6.5 pp higher than in the historical data. For 2011, which was a short interlude between the two crises, the dynamics of the counterfactual scenario coincides with the one of the actual data. As to the sovereign debt crisis, according to the estimates of Busetti and Cova (2013) the corresponding overall GDP loss amounts to nearly 7 pp. In the counterfactual simulation, average annual growth turns out to be slightly below the 2002-2007 average. Hence, at the end of 2013, the level of GDP in the counterfactual scenario is over 13 pp higher than the corresponding historical data. For 2014-15 quarterly GDP growth, as well as the evolution of the other relevant macroeconomic variables, is assumed to be in line with actual data.

\section{Reconstructing the stock of bad debts}

The flow of new bad debts - denoted as $N E W B A D L O A N S_{t}$ - can be obtained by inverting the definition of the new bad debt rate (1):

$$
N E W B A D L O A N S_{t}=\frac{B D I M P_{t}}{400} \cdot\left(L O A N S_{t-1}-B A D L O A N S_{t-1}\right)
$$

Given the outstanding amount of bad debts $\left(B A D L O A N S_{t-1}\right)$, it is possible to derive the current stock as follows:

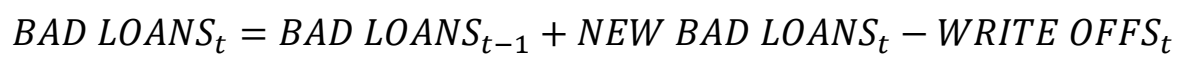

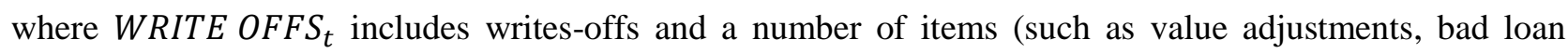
sales, etc.) which are not modelled (and are kept unchanged in the counterfactual simulation). 


\section{Results}

The effects of the two crises on the Italian economy are assessed by computing the difference between the counterfactual simulation ("no-crises" scenario) and the baseline simulation, which replicates the historical data up until the end of $2015 .{ }^{4}$ In particular, using equation (3) one can obtain the new bad debt rate (for loans to non-financial corporations) consistent with the counterfactual dynamics of its determinants $\left(T_{t}, G A P_{t}, O N F I N_{t}\right)$. Figure 3 shows the evolution of the flow of new bad loans to non-financial corporations in the data and in the counterfactual scenario.

Most of the dynamics of the dependent variable may be attributed to the effects of the evolution of the variable $G A P_{t}$. The larger GDP growth implies a substantially lower rate of new bad loans to non-financial corporations. At the end of the simulation horizon, the historically observed rate is about 3 pp higher than the one consistent with the "no-crises" scenario. In the counterfactual simulation, the flow of new bad debt actually declines gradually, albeit moderately, from the peak of late 2008 - early 2009, rather than rising sharply as in the historical data.

Figure 4 compares the evolution of the stock of bad debts in actual data and the counterfactual scenario. In the absence of the two crises - and of the economic policy decisions that were taken to contrast their effects - the stock of non-financial corporations' bad debts at the end of 2015 would have reached $€ 52$ billion, instead of $€ 143$ billion. In the counterfactual scenario, the level at the end of 2015 is only 1.7 times larger than the one observed at the end of 2007; in actual data, the observed level was almost 5 times as large. As a share of total outstanding loans to non-financial corporations, bad debts rose at about 17.9 per cent at the end of 2015; had the two crises never occurred, it would have been around 5 per cent, roughly in line with the pre-crisis level.

\footnotetext{
${ }^{4}$ The difference between the two simulations reflects the different assumptions concerning the factors affecting the dynamics of TBDIMP. As such, the residuals underlying the corresponding estimated equations in the baseline simulation are also included in the counterfactual simulation.
} 


\section{References}

Albertazzi, U., Notarpietro, A. and S. Siviero, 2016. An inquiry into the determinants of the profitability of Italian banks, forthcoming, Questioni di Economia e Finanza (Occasional Papers).

Banca d'Italia (2016) Financial Stability Report, n.1, April.

Busetti, F. and P. Cova, 2013. The macroeconomic impact of the sovereign debt crisis: a counterfactual analysis for the Italian economy, Questioni di Economia e Finanza (Occasional Papers) 201.

Caivano, M., Rodano, L. and S. Siviero, 2010. The transmission of the global financial crisis to the Italian economy. A counterfactual analysis, 2008-2010, Questioni di Economia e Finanza (Occasional Papers) 64.

Parigi, G. and S. Siviero, 2000. "An Investment-Function-Based Measure of Capacity Utilisation. Potential Output and Utilised Capacity in the Bank of Italy's Quarterly Model," Temi di discussione (Economic working papers) 367, Bank of Italy, Economic Research and International Relations Area 
Figure 1. New bad debt rate

$$
\text { (per cent) }
$$

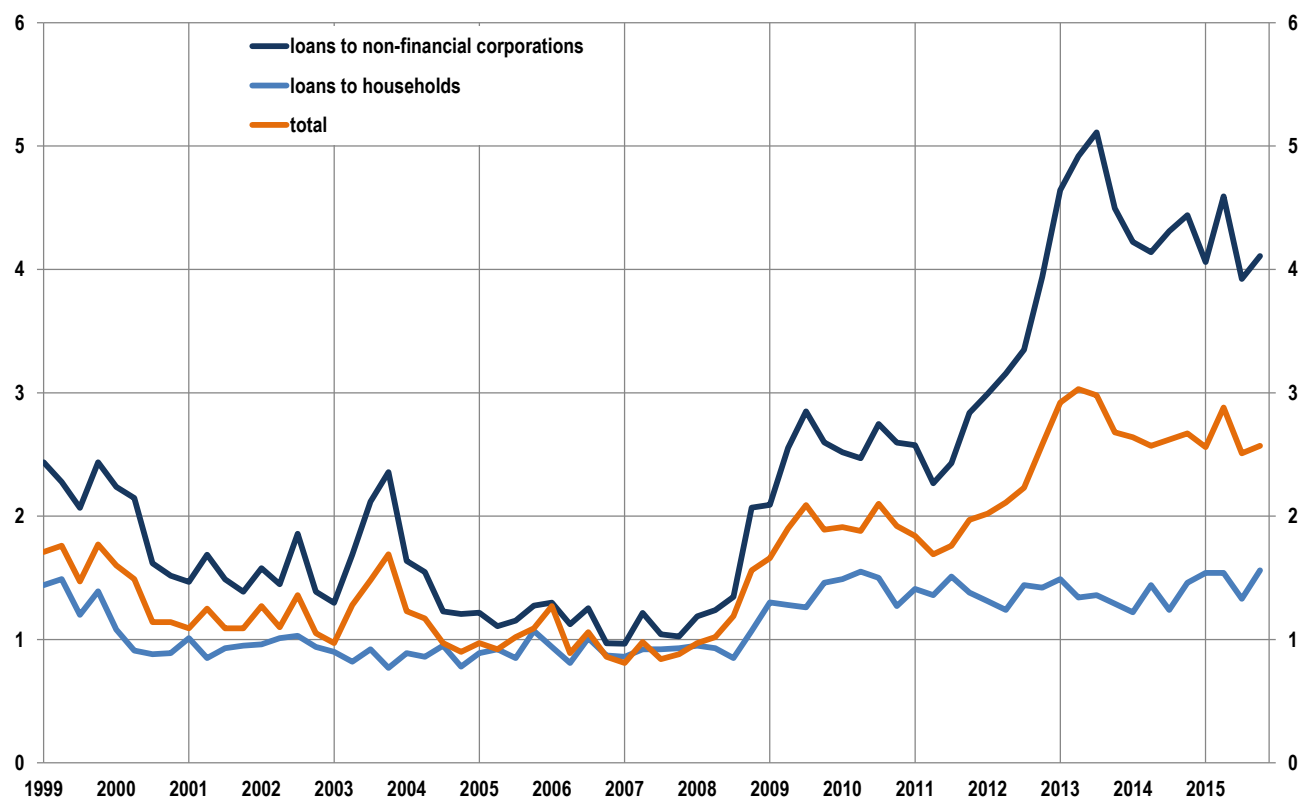

Table 1. Estimate of the equation for the new bad debt rate (loans to non-financial corporations)

$$
\begin{gathered}
\text { TBDIMP } \\
t=-1.5175+0.67173 * T B D I M P_{t-1}+0.0137 * T R_{t}-0.06734 * G A P_{t-1}+0.0026 * O N F I N_{t} \\
(-5.123)
\end{gathered}
$$

$\begin{array}{llr}\text { R-Squared } & : & 0.95422 \\ \text { Adjusted R-Squared } & : & 0.94925 \\ \text { Durbin-Watson Statistic } & : & 1.7006 \\ \text { Sum of squares of residuals } & : & 0.93118 \\ \text { Standard Error of Regression } & : & 0.10592 \\ \text { Log of the Likelihood Function } & : & 82.12 \\ \text { F-statistic ( 9, 83) } & : & 192.21 \\ \text { Mean of Dependent Variable } & : & -3.7289 \\ \text { Number of Observations } & : & 93 \\ \text { Number of Degrees of Freedom } & : & 83 \\ \text { Current Sample } & : & 1991420144\end{array}$


Figure 2. Response of new bad debt rate to a 1p.p. shock to output gap, different years

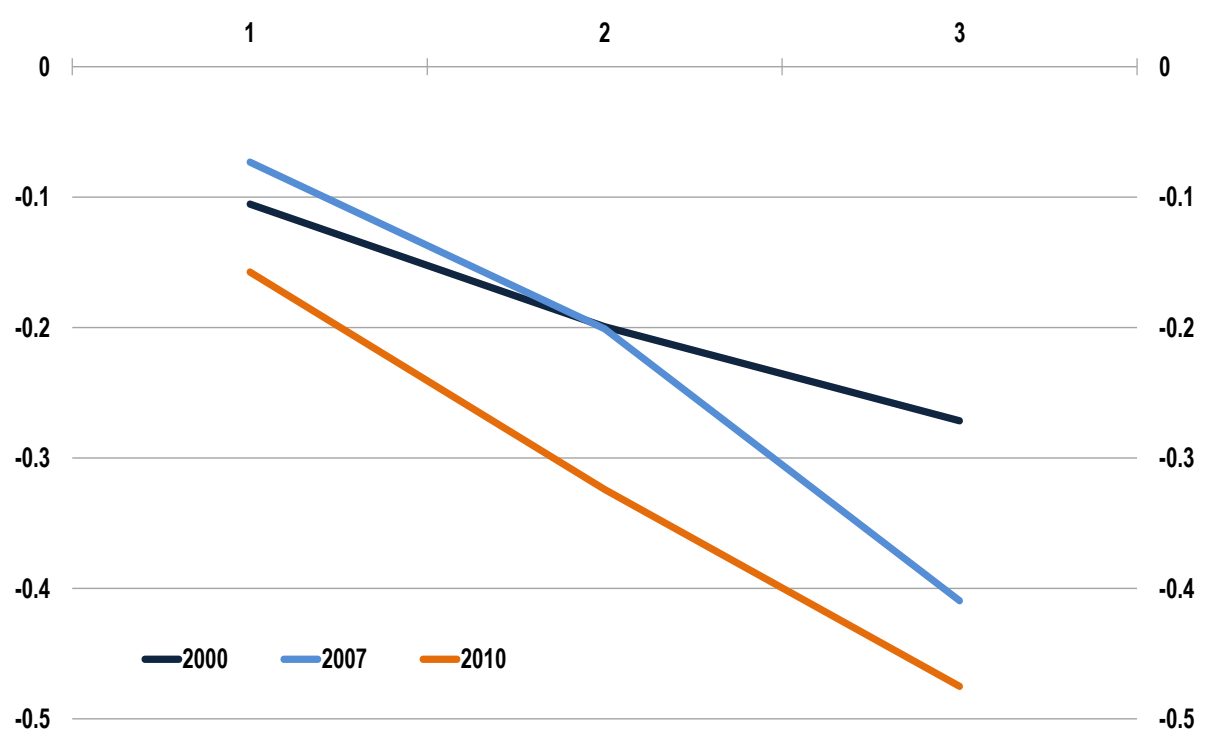

Note: horizontal axis: years.

Figure 3. New bad debt rate of non-financial corporations: historical data and "no-crises" scenario (per cent)

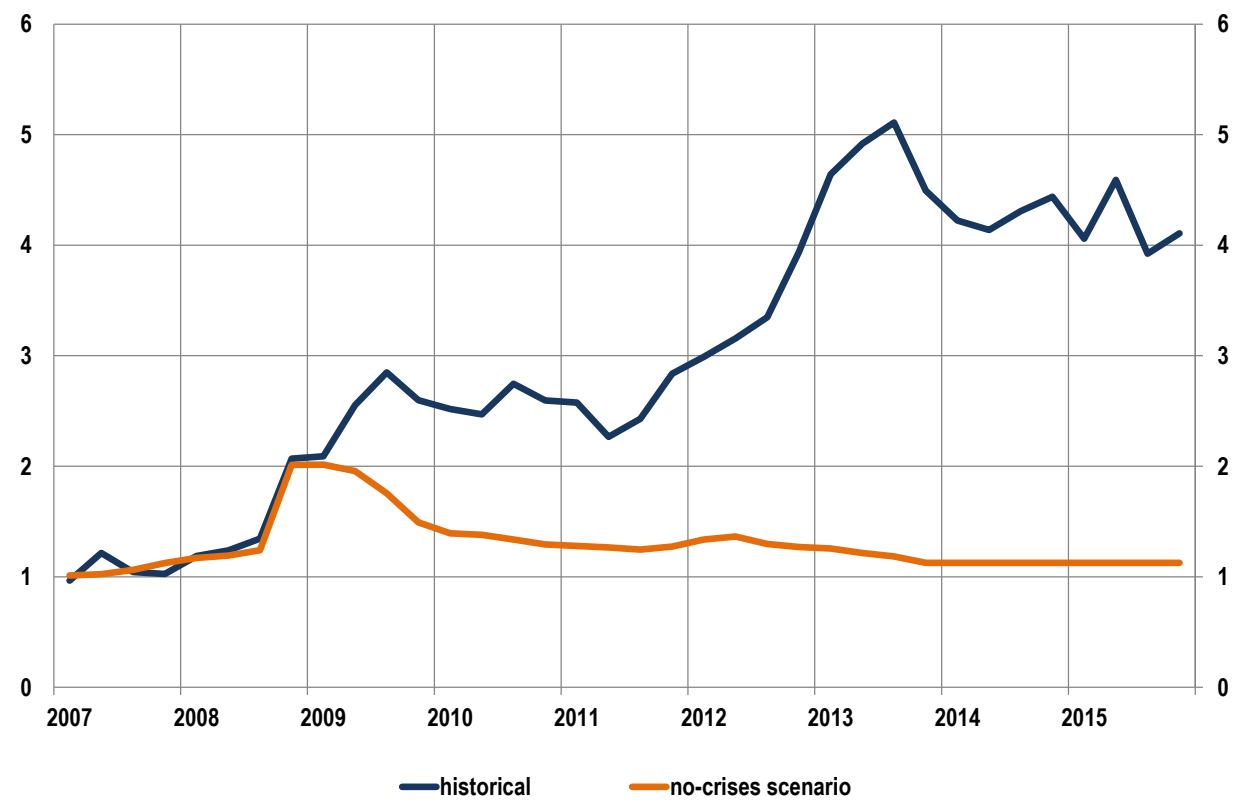


Figure 4. Stock of bad debt of non-financial corporations: historical data and "no-crises" scenario (billions of $€$ )

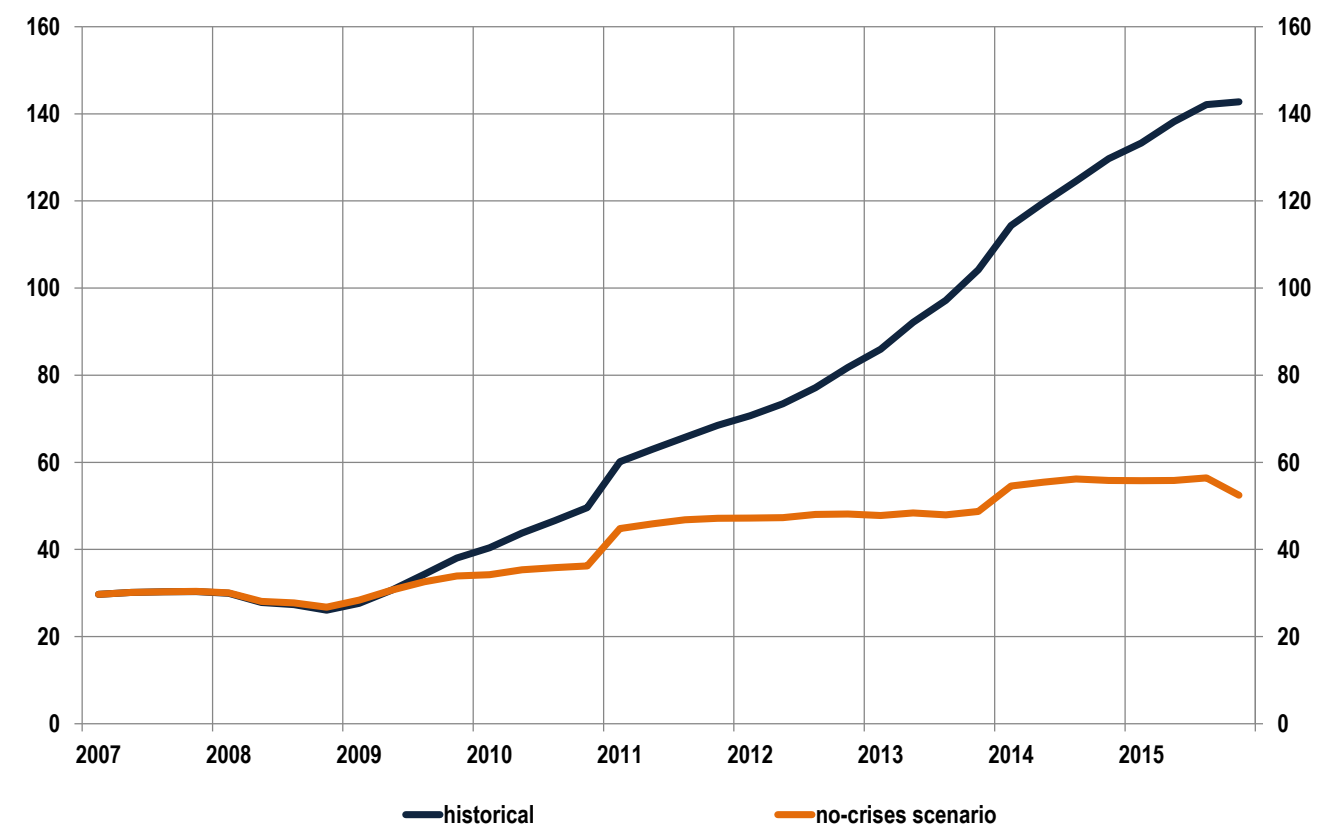

